\title{
A pressão antrópica nas áreas de captação de água no município de Antonina - Estado do Paraná
}

\author{
Anthropogenic pressure in water catchment areas in the Municipality of Antonina - Paraná State
}

\author{
Celso Valério Antunes ${ }^{1}$ \\ Ana Paula Nascimento Lourenço ${ }^{2}$ \\ Emerson Luís Pawoski da Silva ${ }^{3}$ \\ Wanderley Hermenegildo ${ }^{4}$ \\ Allan Paul Krelling 5 \\ Emerson Luis Tonetti ${ }^{6}$ \\ Everaldo dos Santos $^{7}$
}

\section{Resumo}

As áreas urbanas das cidades crescem sobre espaços vegetados e as interações socioambientais são alvos de debates constantes sobre a gestão de recursos e territórios. Neste contexto, os serviços ecossistêmicos, que são bens e serviços providos pela natureza e provêm relações benéficas à população, garantem o bem-estar da população e sua qualidade de vida. Como exemplo, temos o fornecimento de água potável. Contudo, a exploração destes recursos hídricos pode resultar em uma pressão antrópica sobre o meio ambiente. Este estudo tem como objetivo avaliar a pressão antrópica de crescimento urbano sobre o serviço ambiental de provisão da água potável do município de Antonina, no litoral do Paraná. Foram utilizadas imagens de satélite no período de 2000 a 2014 para inferência da cobertura da terra nos entornos dos 5 pontos de captação de água e para diagnóstico do crescimento da macrozona urbana do município. Essas informações foram comparadas com o crescimento populacional e a quantidade de água captada. Pode-se inferir que a captação de água tem volume constante, apesar do crescimento urbano, demonstrando que até o presente momento o serviço ecossistêmico da água em Antonina não sofreu impacto.

Palavras-chave: Serviço ecossistêmico. Conservação. Urbanização.

\begin{abstract}
Urban areas of cities grow over vegetated spaces and socio-environmental interactions are the targets of constant debates on the management of resources and territories. In this context, ecosystem services, which are goods and services provided by nature and provide beneficial relations to the population, guarantee the well-being of the population and its quality of life. As an example, we have the supply of drinking water. However, the exploitation of these water resources

\footnotetext{
1 Mestrando no Programa de Pós-Graduação em Ciência, Tecnologia e Sociedade do Instituto Federal do Paraná/Campus Paranaguá. Docente FAE Business School. Curitiba-PR. E-mail: celso.v.antunes@bol.com.br

2 Mestranda no Programa de Pós-Graduação em Ciência, Tecnologia e Sociedade do Instituto Federal do Paraná/Campus Paranaguá. E-mail: bessymamufpr@gmail.com

3 Mestrando no Programa de Pós-Graduação em Ciência, Tecnologia e Sociedade do Instituto Federal do Paraná/Campus Paranaguá. E-mail: emprovoski@gmail.com

${ }^{4}$ Biólogo da Universidade Estadual do Paraná/Campus Paranaguá. E-mail: wandebio@gmail.com

${ }^{5}$ Doutor em Sistemas Costeiros e Oceânicos, Docente do Instituto Federal do Paraná/Campus Paranaguá. E-mail: allan.krelling@ifpr.edu.br

6 Doutor em Geografia. Docente do Instituto Federal do Paraná/Campus Paranaguá. E-mail: emerson.tonetti@ifpr.edu.br

7 Doutor em Engenharia Florestal. Docente do Instituto Federal do Paraná/Campus Paranaguá. E-mail: everaldo.santos@ifpr.edu.br
} 
can result in anthropogenic pressure on the environment. This study aims to evaluate the anthropic pressure of urban growth on the environmental service of drinking water supply in the municipality of Antonina, on the coast of Paraná State - Brazil. Satellite images were used in the period from 2000 to 2014 to infer land cover around the 5 water catchment points and to diagnose the growth of the city's urban macrozone. This information was compared with the population growth and the amount of water captured. It can be inferred that water abstraction has a constant volume, despite the urban growth, demonstrating that until now the ecosystem service of water in Antonina has not suffered impact.

Keywords: Ecosystem service. Conservation. Urbanization.

\section{Introdução}

As interações socioambientais são alvos de debates constantes. Especialmente sobre a gestão de recursos e territórios. Essas interações decorrem da necessidade de mediar a relação, muitas vezes dependente, entre sociedade e natureza. São comuns os casos de catástrofes e poluição (LATOUR, 2013). Contudo, há relações benéficas, especialmente para a sociedade, como os serviços ecossistêmicos, que são bens e serviços providos pela natureza (COSTANZA et al., 1997). A demonstração desses serviços torna-se mais difícil conforme a inserção tecnológica, uma vez que o excesso de artefatos, processos e técnicas faz o ciclo parecer complexo (LATOUR, 2013; RICÁRDEZ, 2019).

As áreas urbanas das cidades crescem sobre espaços vegetados, através de: (1) ramificações originadas por vias; (2) construção de edificações residenciais e comerciais; (3) criação de áreas rurais ou periurbanas; (4) formação de lotes e quadras, com ou sem pavimentação (RICÁRDEZ, 2019). Esse processo influi sobre o manejo e ação dos serviços ecossistêmicos locais, i.e., bens e serviços oferecidos pela natureza como vegetação, água, solo, fauna e flora (COSTANZA et al., 1997). Conforme apresentado por Adler e Tanner (2015), as dinâmicas e ciclagens ecológicas de matéria e energia tem menor rotatividade em ambientes urbanos quando comparadas com ambientes naturais, e recomenda-se a conservação de recursos locais para provisão de uma qualidade de vida mínima à população. Há normas ambientais que definem tipos de uso para determinados espaços de acordo com suas características ecológicas a fim de conservar um mínimo de qualidade ambiental (COSTANZA et al., 1997). O Código Florestal Brasileiro (Lei 12.651/ 2012) define que áreas adjacentes a pontos espaciais de interesse ecológico devem ser preservadas. Esses espaços são chamados de Áreas de Preservação Permanentes (APP’s) e em casos específicos, há no entorno das APP's uma zona de amortecimento de efeitos antrópicos (BRASIL, 2012), que é bastante utilizada nos processos de licenciamento de atividades com potencial causador de dano ambiental (CUNICO, 2016). Esse processo legislativo está baseado na conservação e preservação dos serviços 
ecossistêmicos e, portanto, quando infringido tem consequências negativas à população humana (COVIZZI; CAMARGO; GOBBI, 2017).

Este estudo teve como objetivo avaliar a pressão antrópica do crescimento urbano em relação ao serviço ecossistêmico de provisão de água potável no município de Antonina, situado no litoral do Paraná. O município de Antonina encontra-se inserido em um dos pontos ainda preservados da Mata Atlântica paranaense, com elevado potencial de serviços ecossistêmicos e biodiversidade, de forma que a manutenção da preservação deste ecossistema é fundamental para garantir a provisão destes serviços à sua população. Para esse fim, foram utilizadas imagens de satélite temporais para observação do crescimento urbano em direção aos pontos de captação, bem como a relação desse evento com a qualidade do serviço.

\section{Metodologia}

O município de Antonina está localizado na região litorânea do Paraná e é adjacente a Serra do Mar. As massas úmidas que vem do Oceano Atlântico são represadas por esse acidente topográfico e assim criam um micro-clima com umidade consideravelmente elevada, que corresponde ao clima Cfa da região pela classificação de Köppen-Geiger (ALVARES et al., 2014). Nesse espaço localizam-se diversas unidades de conservação como a Área de Proteção Ambiental de Guaraqueçaba, Reserva Natural da Guaricica dentre outros (CUNICO, 2016). O município se encontra na mesorregião metropolitana de Curitiba e, mais precisamente na microrregião de Paranaguá, tendo como municípios limítrofes: Campina Grande do Sul, Morretes, Guaraqueçaba e Paranaguá, e pelas vias de acesso estando a uma distância de aproximadamente $50 \mathrm{~km}$ de Paranaguá e a $90 \mathrm{~km}$ da capital Curitiba (CUNICO, 2016) (FIGURA 1). 
FIGURA 1 - LOCALIZAÇÃO DOS PONTOS DE CAPTAÇÃO DE ÁGUA DO MUNICÍPIO DE ANTONINA - PR.

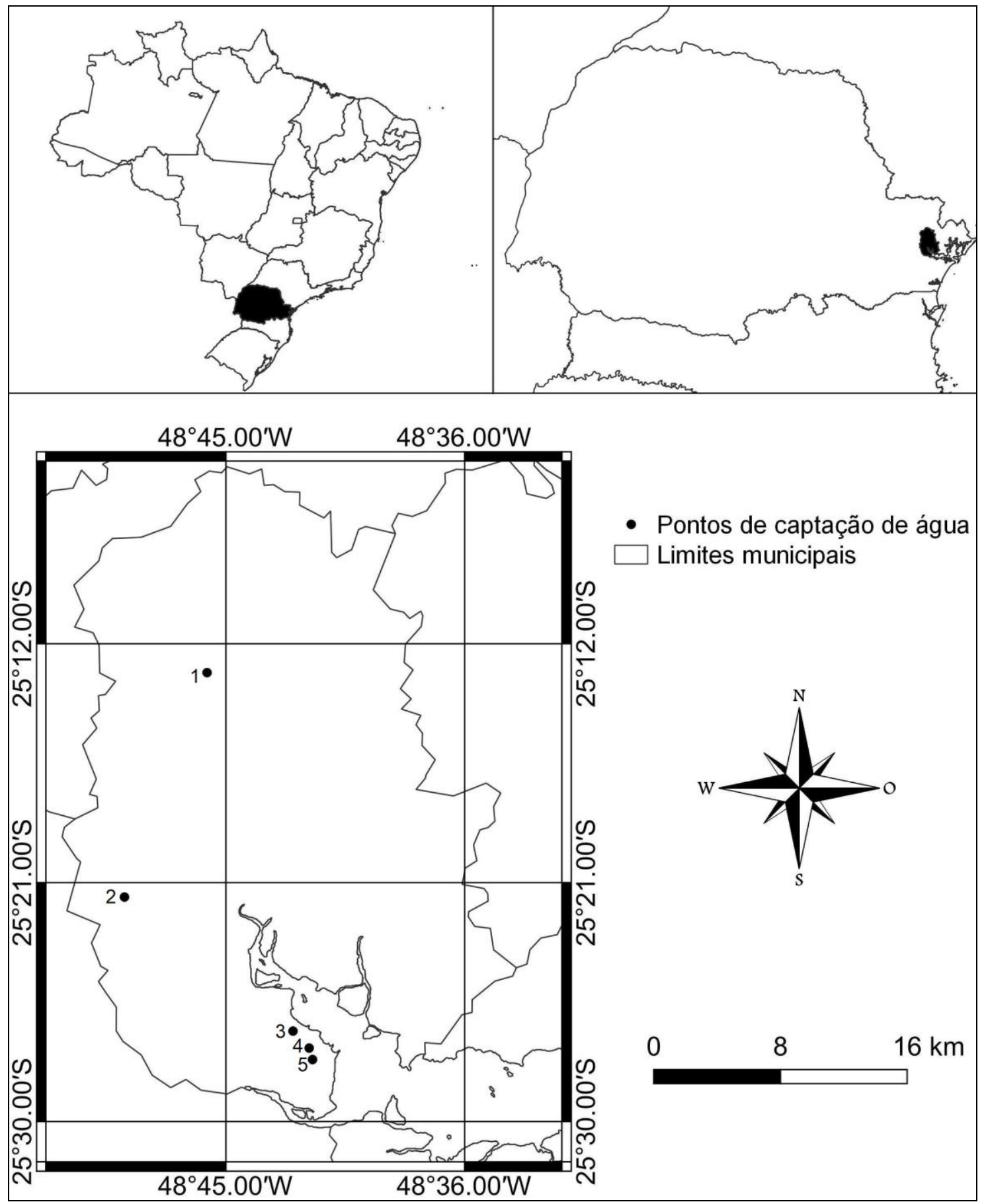

LEGENDA: 1- Rio Cotia 1; 2-Rio Xaxim; 3- Ribeirão Matarazzo; 4 - Sistema Itapema 1; 5- Sistema Itapema 2. FONTE: Dados fornecidos pela SAMAE, 2019.

A planície litorânea possui características singulares relacionadas ao crescimento populacional, pelo fato de estar no nível do mar. Os municípios crescem em sentido horizontal e não vertical, não cobrindo os topos de morros. Segundo o último censo, Antonina contava com uma população de 18.849 habitantes (IBGE, 2019). O município tem a maior parte de sua população 
residindo em área urbana, cerca de $85 \%$ da população, e os outros $15 \%$ estão distribuídos na área rural e contempla a densidade demográfica de $21 \mathrm{hab} / \mathrm{km}^{2}$. Antonina tem como principais fontes de renda as atividades ligadas à prestação de serviços, indústria e agricultura, tendo como destaque àquelas relacionadas ao setor portuário (CUNICO, 2016).

O abastecimento de água ocorre pelo Serviço Autônomo Municipal de Água e Esgoto de Antonina - SAMAE. Anteriormente à criação da SAMAE, o sistema de captação de água era feito através de uma nascente pelo bairro Saivá e conduzida até um reservatório, no bairro Guarapirocaba - atualmente conhecido como bairro da caixa d'água - em seguida a água era distribuída sem tratamento para a população antoninense. Na época o volume captado era de $5 \mathrm{~L} / \mathrm{s}$. O projeto da SAMAE foi elaborado, estimando o crescimento do município em 20 anos, presumindo uma população de 18.000 habitantes, com um consumo diário de 1,85 L/s, sem previsão do uso industrial (ANTONINA, 2019).

As distâncias dos pontos de captação do serviço estudados em linha reta para macrozona urbana são: aproximadamente $24 \mathrm{~km}$ para Rio Cotia 1; $12 \mathrm{~km}$ para Rio Xaxim; 0,5 km para Sistema Itapema 1; valores menores que 0,5 km para Ribeirão Matarazzo e Sistema Itapema 2.

O presente estudo mostra a conservação da vegetação e a presença de pressão antrópica nos 6 pontos de captação de água (FIGURA 1) dispostos no território de Antonina. Desses 5 pontos, 2 foram considerados distantes (Rios Cotia 1 e Xaxim) e 3 próximos (Sistema Itapema 1 e 2 e Ribeirão Matarazzo) da macrozona urbana de Antonina. Para tal, foi utilizado o software Google Earth Pro para imagens de satélite.

O histórico da conservação dos pontos de captação de água foi determinado por imagens de satélite dos anos de 2004 e 2014, tendo-se como Área de Preservação Permanente um raio de 100 metros, conforme apontado pelo Código Florestal para pontos de captação e um adendo de 50 metros que compreendem uma zona de amortecimento (BRASIL, 2012), totalizando um raio de 150 metros. As imagens foram avaliadas conforme cobertura da terra, considerando-se a vegetação arbórea e/ ou arbustiva como indicativo de conservação. Esses tipos de vegetação foram identificados conforme notável variação da quantidade de sombras em áreas verdes (COVIZZI; CAMARGO; GOBBI, 2017). Para esse fim, dentro do raio estabelecido como APP e área de amortecimento, foram identificadas as áreas com ausência de vegetação arbórea e/ ou arbustiva em três períodos diferentes: 2000 a 2005; 2006 a 2010 e 2011 a 2015.

A ausência de vegetação em cada ponto e em cada período foi identificada por polígonos construídos com ferramentas do Google Earth Pro. As áreas calculadas dos polígonos foram utilizadas para comparar as variações espaciais (entre pontos) e temporais (entre períodos), através 
do teste chi-quadrado de Pearson $\left(\mathrm{X}^{2}\right)$ considerando a significância para valores de "p" de 0,05 ; 0,01 e 0,001 . Os testes para observar diferença de cobertura da terra nas áreas foram feitos, (1) entre as localidades próxima e distante da macrozona urbana e (2) entre os pontos de captação, dentro das localidades próxima e distante da macrozona urbana.

As informações sobre a população residente e usuária do sistema foram baseados nas fontes do Instituto Brasileiro de Geografia e Estatística - IBGE, Instituto Paranaense de Desenvolvimento Econômico e Social - IPARDES e Departamento de Informática do Sistema Único de Saúde do Brasil - DATASUS, e relacionadas com a capacidade de provisão e conservação dos pontos de captação.

\section{Resultados e discussão}

A área total de cada entorno foi $70.650 \mathrm{~m}^{2}$, com base no raio de 150 metros em um círculo. O espaço coberto por vegetação arbórea e/ou arbustiva está apresentado graficamente (TABELA 1 e FIGURA 2). A imagem de satélite do ponto Rio Xaxim para o período 2000 a 2005 se mostrou de difícil interpretação e considerou-se esse dado como não encontrado, embora provavelmente seja similar aos posteriores.

TABELA 1 - COBERTURA DA TERRA NOS ENTORNOS DOS PONTOS DE CAPTAÇÃO DE ÁGUA.

\begin{tabular}{cccc}
\hline Ponto de coleta & \multicolumn{3}{c}{ Área não vegetada (\%) } \\
\cline { 2 - 4 } & 2000 a & 2006 a & 2011 a \\
& 2005 & 2010 & 2015 \\
\hline Rio Cotia 1 & 4,35 & 0 & 0 \\
Rio Xaxim & $*$ & 1,59 & 1,59 \\
Ribeirão Matarazzo & 19,31 & 19,31 & 20,62 \\
Sistema Itapema 1 & 6,57 & 5,11 & 5,03 \\
Sistema Itapema 2 & 38,36 & 25,80 & 21,46 \\
\hline
\end{tabular}

FONTE: Dados retirados do Google Earth Pro em junho de 2019. ORG.: dos Autores, 2019. 
FIGURA 2 - EVOLUÇÃO DA ÁREA NÃO VEGETADA (\%) DOS ENTORNOS DOS PONTOS DE CAPTAÇÃO AO LONGO DOS PERÍODOS.

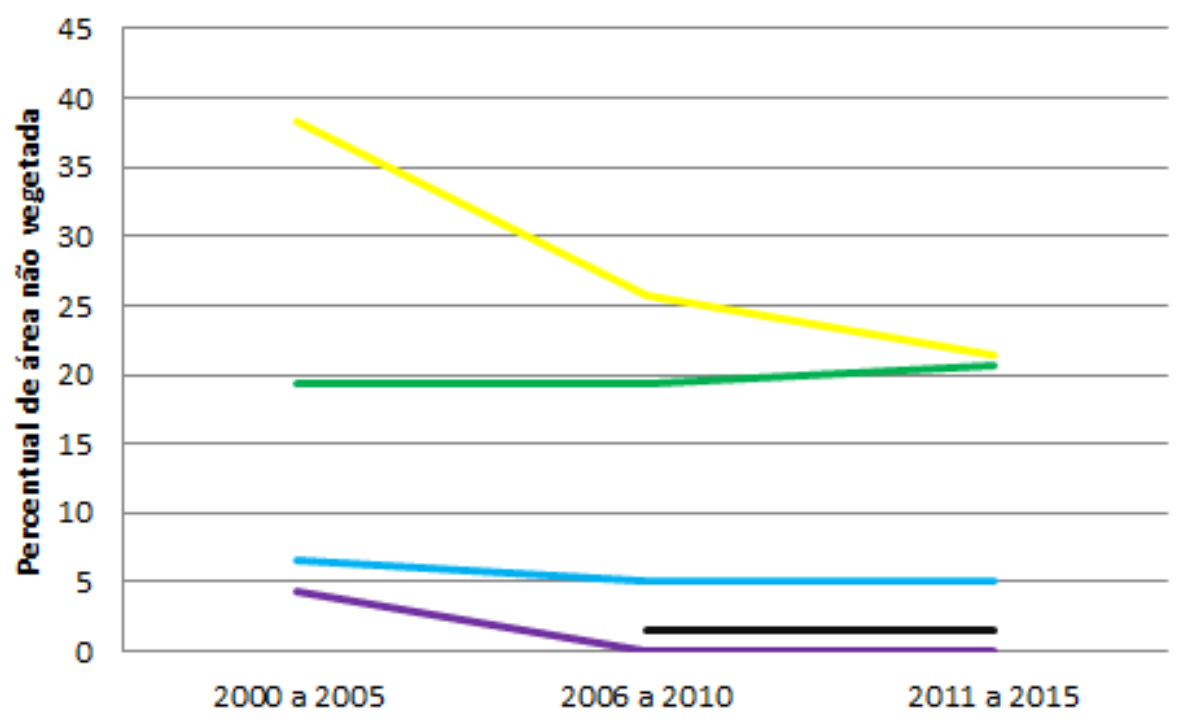

LEGENDA: roxo: Rio Cotia 1; preto: Rio Xaxim; verde: Ribeirão Matarazzo; azul: Sistema Itapema 1; amarelo: Sistema Itapema 2.

FONTE: Dados retirados do Google Earth Pro em junho de 2019.

A vegetação arbórea e/ ou arbustiva aumentou para todos os pontos, a exceção do Sistema Itapema 2, cujo espaço antropizado variou entre $20 \%$ e $40 \%$. As distâncias entre as áreas não vegetadas e o ponto de captação também (FIGURA 3) são maiores quando distantes da macrozona urbana, com exceção para o ponto Ribeirão Matarazzo que não se enquadrou nesse cenário. Em relação a distância da macrozona urbano para os pontos de captação constatou-se que a área de ocupação humana invade os pontos de captação mais próximos, atingindo as APP's, e inicia-se o processo de invasão ao ponto Rio Xaxim no último período na zona de amortecimento. O ponto com maior distância de área não vegetada é o Rio Cotia 1, enquanto que o menor, é Sistema Itapema 2.

FIGURA 3 - DISTÂNCIA DE ÁREA NÃO VEGETADA DOS PONTOS DE CAPTAÇÃO (METROS).

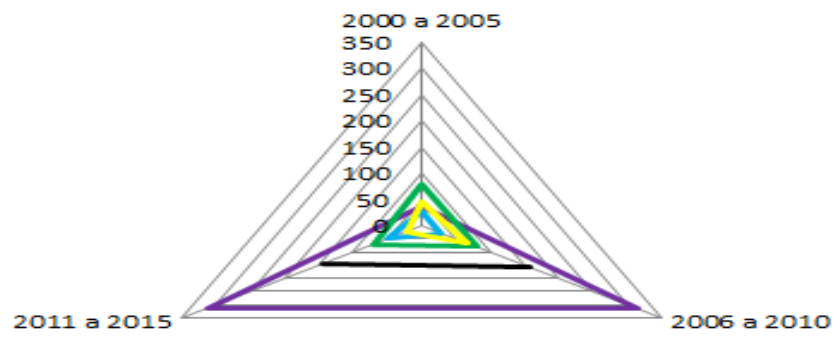

LEGENDA: roxo: Rio Cotia 1; preto: Rio Xaxim; verde: Ribeirão Matarazzo; azul: Sistema Itapema 1; amarelo: Sistema Itapema 2.

FONTE: Dados retirados do Google Earth Pro em junho de 2019. 
Foram encontradas diferenças estatísticas significativas para a cobertura da terra entre as localidades e a distante é que apresentou diferença, e entre pontos na localidade próximo com os pontos Ribeirão Matarazzo e Sistema Itapema 2 sendo significativos, indicado leve aumento e redução de área não vegetada para o primeiro e segundo, respectivamente (TABELA 2).

\section{TABELA 2 - ANÁLISE ESTATÍSTICA PARA A COMPARAÇ̃̃O ENTRE ÁREAS NÃO VEGETADAS DOS PONTOS DE COLETA.}

\begin{tabular}{|c|c|c|c|}
\hline Ponto de coleta & Localidade & Entre localidades & $\begin{array}{c}\text { Entre pontos nas } \\
\text { localidades }\end{array}$ \\
\hline Rio Cotia 1 & \multirow[b]{2}{*}{ Distante } & & \multirow[b]{2}{*}{$12,249 * *$} \\
\hline Rio Xaxim & & & \\
\hline Ribeirão Matarazzo & \multirow{3}{*}{ Próximo } & $225,59 * * *$ & \multirow{3}{*}{$214,69 * * *$} \\
\hline Sistema Itapema 1 & & & \\
\hline Sistema Itapema 2 & & & \\
\hline
\end{tabular}

Em todo período observado, de acordo com os dados obtidos da SAMAE (2019), o sistema de abastecimento de água de Antonina (i.e., captação e tratamento) é primário e não sofreu alteração desde 2002. Desta forma, o volume captado e tratado permaneceu inalterado neste período. A produção média de água tratada é de aproximadamente $81 \mathrm{~L} / \mathrm{s}$. São estimadas perdas na rede de abastecimento de aproximadamente $35 \mathrm{~L} / \mathrm{s}$ de seu volume tratado. Os pontos mais distantes da macrozona urbana, Rio Cotia 1 e Rio Xaxim apresentaram maior vazão, junto com o Sistema Itapema 1, enquanto os dois de maior proporção de área não vegetada as menores vazões (TABELA $3)$.

TABELA 3 - VAZÃO DO SISTEMA DE CAPTAÇÃO DE ÁGUA DE ANTONINA.

\begin{tabular}{|c|c|c|}
\hline Ponto de coleta & $\begin{array}{l}\text { Sistema de } \\
\text { captação }\end{array}$ & $\begin{array}{c}\text { Vazão (L/s) } \\
\text { Entre } \\
\text { localidade }\end{array}$ \\
\hline Rio Cotia 1 & Rio Jantador & 35 \\
\hline Rio Xaxim & Rio Xaxim & 35 \\
\hline Ribeirão Matarazzo & $\begin{array}{c}\text { Sistema } \\
\text { Independente } \\
\text { da Penha }\end{array}$ & 6 \\
\hline Sistema Itapema 1 & $\begin{array}{c}\text { Sistema } \\
\text { Independente } \\
\text { Itapema } 1\end{array}$ & 28 \\
\hline Sistema Itapema 2 & $\begin{array}{c}\text { Sistema } \\
\text { Independente } \\
\text { Itapema } 2 \\
\end{array}$ & 12 \\
\hline
\end{tabular}

FONTE: SAME/PREFEITURA DE ANTONINA. Org.: dos Autores, 2019. 
Segundo dados do IPARDES (2019a) o município de Antonina sofreu um declínio populacional de aproximadamente 5,88\%, entre os anos de 2004 e 2014 e segue a tendência dos últimos anos de redução de sua população em cerca de 13\%, (FIGURA 4).

FIGURA 4 - CRESCIMENTO POPULACIONAL DE ANTONINA.

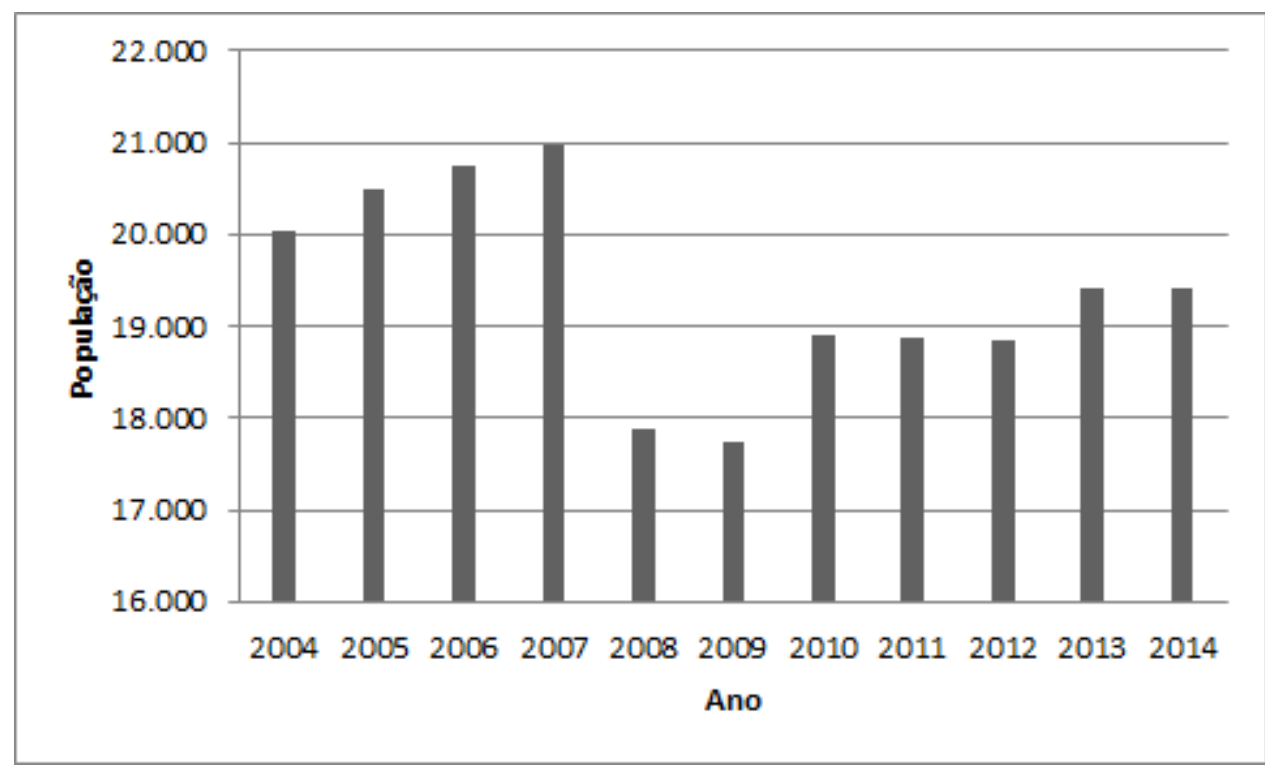

FONTE: DATASUS, 2019; IPARDES ,2019a; IBGE 2019.

Segundo estudos do IPARDES (2019a) sobre a projeção da população paranaense para 2030, 252 municípios do Estado terão uma redução na população nas próximas duas décadas. De modo geral 52,7\% dos municípios brasileiros terão suas populações reduzidas nos próximos anos. A redução populacional não está associada ao empobrecimento dos municípios, pois em sua maioria, tais cidades possuem atividades relacionadas ao agronegócio, e devido a isso, a geração de empregos no setor deve continuar. De certo modo, os municípios que atualmente apresentam proporções mais elevadas de população rural tendem a manter perdas nos próximos períodos, embora diversas cidades já tenham acompanhado essa redução da população urbana há alguns anos (SANTOS; MAGALHÃES; DELGADO, 2019).

Observou-se que o crescimento populacional é diferente do avanço territorial urbano e rural, ou seja, a população do município diminuiu entre os anos de 2004 e 2014, mas ocorreu um avanço significativo do território principalmente na área rural. De acordo com o IPARDES (2019b), pode se observar o aumento das ligações de abastecimento de água no município de Antonina entre os anos de 2004 e 2014 (FIGURA 5). 
FIGURA 5 - CRESCIMENTO DE LIGAÇÕES DE ÁGUA EM ANTONINA.

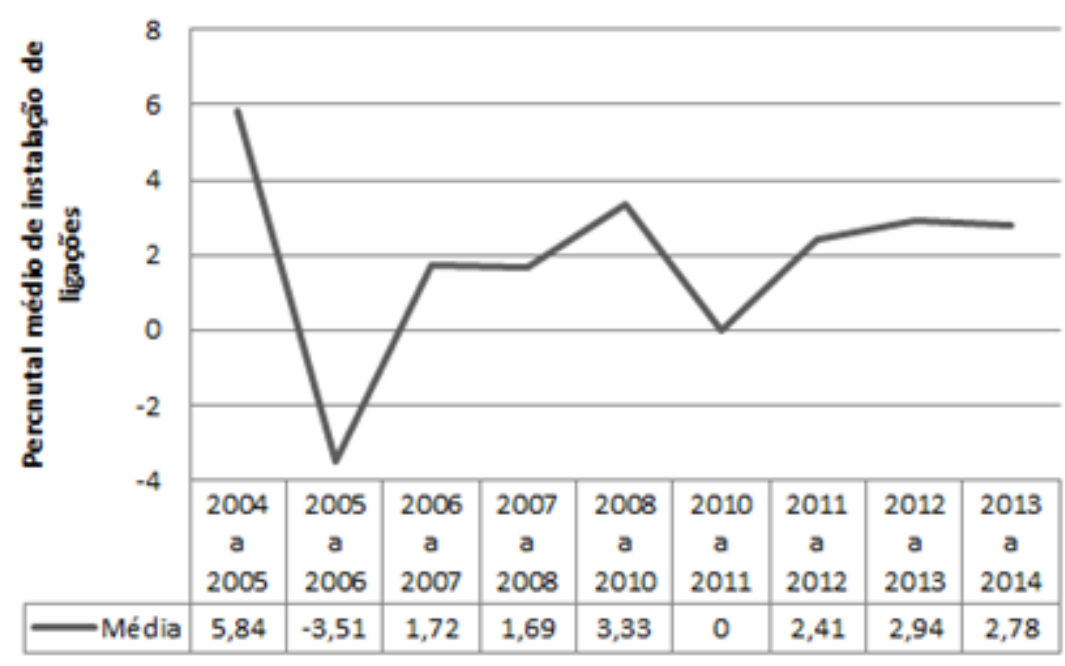

FONTE: IPARDES, 2019b.

Ainda que tenha ocorrido a redução da população do município de Antonina, foi aberto um novo ponto de captação do serviço ecossistêmico de água, chamado de Rio Cotia 2, no ano de 2019, para atender as necessidades da população. Entre as hipóteses para a abertura desse novo ponto citam-se: o aumento da rede e a ligação à SAMAE que advém após o convênio de cooperação técnica e financeira firmado entre a Fundação Nacional de Saúde - FUNASA e Prefeitura Municipal que visa a Elaboração e Implantação do Plano Municipal de Saneamento Básico de Antonina. De acordo com o decreto da Lei 11.445/ 07, que institui o Plano Nacional de Saneamento Básico, que obriga todos os municípios a elaborarem seu Plano Municipal de Saneamento Básico (BRASIL, 2007); e consumo exacerbado de água em períodos festivos, como Carnaval, e durante os meses do verão.

Nos anos de 2005 e 2006, houve uma atualização nos dados do IPARDES (2019b), no qual se percebe o desligamento de abastecimento nos registros via sistema da SAMAE em mais de 3,5\% das 6.011 unidades cadastradas no período, sem indicação do motivo.

Como exposto, a pressão antrópica do crescimento urbano interferiu significativamente na conservação e produção dos mananciais utilizados no município de Antonina entre os anos de 2000 e 2014, enquanto a populacional não o fez. Demandas públicas, como exigências legislativas, foram relevantes nesse contexto e imprimiram a criação de um novo ponto de captação.

\section{Considerações Finais}

No município de Antonina os cinco principais pontos de captação têm seu entorno conservado e observou-se redução populacional, apesar do aumento da ocupação humana sobre os 
pontos localizados dentro da macrozona urbana da cidade e da quantidade de ligações entre os anos de 2004 e 2014.

Conclui-se que a pressões antrópicas do crescimento urbano foram significativas, e as populacionais não, para a conservação do serviço ecossistêmico da água de Antonina, embora tenha sido mantida a mesma qualidade no período estudado.

Os dados desse estudo foram obtidos com imagens de satélite, consultas a SAMAE e literatura, sendo recomendada a observação in situ dos espaços analisados para ampliar futuras análises e tomadas de decisão.

\section{Referências}

ADLER, F.; TANNER, C.J. Ecossistemas urbanos: princípios ecológicos para o ambiente construído. 1. ed. São Paulo: Oficina de Textos, 2015.

ALVARES, C.A.; STAPE, J.L.; SENTELHAS, P.C.; GONÇALVES, J.L.M.; SPAROVEK, G. Köppen's climate classification map for Brazil. Meteorologische Zeitschrift, v.22, n.6, p.711-728, 2014.

ANTONINA. Lei $\mathbf{N}^{\circ}$ 10/68. Disponível em: <https://leismunicipais.com.br/a/pr/a/antonina/leiordinaria/1968/1/10/lei-ordinaria-n-10-1968-cria-o-servico-autonomo-municipal-de-agua-e-esgotosamae-e-da-outras-providencias>. Acesso em: 15 set. 2019.

BRASIL. Lei complementar $\mathbf{n}^{0}$ 11.445, de 5 de janeiro de 2007. Diário Oficial da União, Brasília, DF, n. 5, 8 jani. 2007. Seção 1, p. 3.

BRASIL. Lei complementar $\mathbf{n}^{0}$ 12.651, de 25 de maio de 2012. Diário Oficial da União, Brasília, DF, n. 137, 28 mai. 2012. Seção 1, p. 1.

COSTANZA, R.; D'ARGE, R.; GROOT, R.; FARBER, S.; GRASSO, M.; HANNON, B.;LIMBURG, K.; NAEEM, S.; O'NEILL, R.V.; PARUELO, J.; RASKIN, R.G.; SUTTON, P.; BELT, M. The value of the world's ecosystem services and natural capital. Nature, v.387, p.253260, 1997.

COVIZZI, M. C.; CAMARGO, D. M.; GOBBI, E. S. Fotointerpretação aplicada à análise das alterações do uso e cobertura da terra e a situação das áreas de preservação permanente. In: PEREZ FILHO, A.; AMORIM, R. R.. (Org.). Os Desafios da Geografia Física na Fronteira do Conhecimento. 1 ed. Campinas: Instituto de Geociências - UNICAMP, 2017, v. 1, p. 264-276, 2017.

CUNICO, C. (Org.) Zoneamento Ecológico-Econômico do Estado do Paraná. Curitiba: ITCG, 2016. 
DATASUS - Departamento de Informática do Sistema Único de Saúde do Brasil. História. Disponível em: <http://tabnet.datasus.gov.br/cgi/deftohtm.exe?ibge/cnv/poptPR.def>. Acesso em: 22 jun. 2019.

IBGE - Instituto Brasileiro de Geografia e Estatística. Antonina. Disponível em: <https://cidades.ibge.gov.br/brasil/pr/antonina/historico>. Acesso em: 22 jun. 2019.

IPARDES - Instituto Paranaense de Desenvolvimento Econômico e Social. Cadernos Estatístico Município de Antonina. Disponível em: $<$ http://www.ipardes.gov.br/cadernos/MontaCadPdf1.php?Municipio=83370\&btOk=ok>. Acesso em: 17 jun. 2019.

IPARDES - Instituto Paranaense de Desenvolvimento Econômico e Social. Abastecimento de água - ligações. Disponível em: <http://www.ipardes.gov.br/imp/imp.php?page=varinfpop\&var=475>. Acesso em: 28 jun. $2019 \mathrm{~b}$.

LATOUR, B. Jamais fomos modernos. 3 ed. Rio de Janeiro: Editora 34, 2013.

RICÁRDEZ, M. Sustentabilidad y Paisaje: retos de interlocución frente a los desafíos de la urbanización. In: DIAS, L.S.; CHÁVEZ, E.S. (orgs). Cartografia biogeográfica e da paisagem. vol 2. Tupã: ANAP, 2019, p.229-270.

SANTOS, H.P.; MAGALHÃES, M.V.; DELGADO, P.R. Projeção da população total dos municípios do Paraná para o período 2016-2030. IPARDES. Disponivel em <http://www.ipardes.pr.gov.br/pdf/indices/projecao_populacao_Parana_2016_2030_set.pdf>. Acesso em 24 de jun. 2019.

Artigo recebido em 17/12/2019. Aceito para publicação em 23/12/2019. 